\title{
Transcription Factor E2F Is Required for Efficient Expression of the Hamster Dihydrofolate Reductase Gene In Vitro and In Vivo
}

\author{
MICHAEL C. BLAKE, ${ }^{1,2}$ AND JANE CLIFFORD AZIZKHAN ${ }^{1,2,3 *}$ \\ Lineberger Cancer Research Center, ${ }^{1}$ Departments of Pediatrics and Pharmacology, ${ }^{3}$ and Curriculum in Genetics, ${ }^{2}$ \\ University of North Carolina, Chapel Hill, North Carolina 27599-7295
}

Received 25 May 1989/Accepted 1 August 1989

\begin{abstract}
The dihydrofolate reductase (DHFR) gene encodes an enzyme important for metabolism and cell growth. We have found multiple DNA-protein interactions within the hamster DHFR gene promoter in vitro. These interactions occur over the consensus binding sites for two eucaryotic transcription factors, Sp1 and E2F. The DHFR E2F consensus site possesses a dyad symmetry and is unique in its location immediately $3^{\prime}$ to the major transcription start site. The interaction of E2F with the DHFR promoter has been detected in HeLa nuclear extracts, confirmed by using partially purified E2F, and characterized by both enzymatic and chemical assays of the DNA-protein interaction. A mutation of the E2F recognition sequence which abolishes E2F binding to the DHFR promoter results in a two- to fivefold decrease of in vitro transcriptional activity and a fivefold reduction of DHFR promoter activity in transient-expression assays. Thus, the interaction of E2F with the DHFR promoter is required for efficient expression of the DHFR gene.
\end{abstract}

Dihydrofolate reductase (DHFR) is a metabolic enzyme involved in the synthesis of purines, thymidylate, and glycine (23). It is considered a housekeeping enzyme, since it is found in small amounts in nearly all cell types and is required for cell growth (21). Although the gene encoding DHFR is widely expressed, this expression is influenced by several factors, including the growth state of the cells, the cell cycle, and the presence of viral infection $(6,21,27)$. The DHFR promoter lacks TATAA and CCAAT DNA sequence motifs, which are regulatory sequence elements found in most eucaryotic promoters transcribed by RNA polymerase II. The DHFR promoter contains multiple copies of GC boxes, which are capable of interacting with the transcription factor Sp1 (5). An additional conserved sequence including the major transcription start site has been identified in the DHFR promoter (1).

The eucaryotic transcription factor E2F was originally identified as a DNA-binding activity in HeLa nuclear extracts (12). This factor binds to two sites in a region of the adenovirus E2 promoter known to be required for E2 promoter activity. E2F binding activity increases upon infection of HeLa cells with wild-type adenovirus; this increase depends on the presence of a functional E1A gene (12). The adenovirus E1A gene product is known to trans-activate several viral and cellular genes by a variety of mechanisms. E2F is hypothesized to be one of the targets of the adenovirus E1A gene product early in adenovirus infection. E2F binding sites have also been identified in the E1A enhancer (13) and the c-myc promoter $(10,24)$; E2F binds to the sequence 5'-TTTCGCGC-3'. DHFR expression is increased by adenovirus infection, although the molecular level at which this increase occurs is unclear $(7,27)$.

One study of the mouse DHFR promoter reported that a fraction of HeLa nuclear extract enriched in $\mathrm{Sp} 1$ bound to the consensus $\mathrm{Sp} 1$ binding sites in the mouse DHFR promoter (5). It also showed that HeLa nuclear extracts depleted of this fraction were incapable of efficient in vitro transcription (5). We report here that an additional factor in HeLa nuclear extracts binds to the hamster DHFR promoter

\footnotetext{
* Corresponding author.
}

in vitro and is required for efficient DHFR expression both in vitro and in vivo. This additional factor appears to be E2F on the basis of its recognition sequence, the comigration of DNA-protein complexes generated in nuclear extracts with those generated by using partially purified E2F, footprinting and methylation interference patterns, and loss of binding after a specific site-directed mutation. The data presented include the mapping of DNA-protein interactions occurring within a DHFR promoter construct known to have transcriptional activity in vitro and in vivo and characterization of the interaction of E2F with the DHFR promoter by DNAbinding assays and site-directed mutagenesis, followed by functional analysis of the role of E2F in DHFR expression.

(This work was conducted by M.C.B. in partial fulfillment of the requirements for the $\mathrm{Ph}$.D. degree from the University of North Carolina, Chapel Hill.)

\section{MATERIALS AND METHODS}

Preparation of nuclear extracts. HeLa-S3 cells were grown in suspension culture and maintained at a density of $4 \times 10^{5}$ to $8 \times 10^{5}$ cells per $\mathrm{ml}$ in Joklik modified essential medium supplemented with $10 \%$ defined calf serum (Hyclone Laboratories, Inc.) and gentamycin-kanamycin. Nuclear extracts were prepared from these cells by an established method (4) with the following modifications. After homogenization of cells in hypotonic medium, nuclei were recovered by centrifugation at $30,000 \times g$ for $30 \mathrm{~s}$. Nuclei were then extracted in buffer $\mathrm{C}\left[20 \mathrm{mM} N\right.$-2-hydroxyethylpiperazine- $N^{\prime}-2$ ethanesulfonic acid (HEPES; pH 7.9), $0.2 \mathrm{mM}$ EDTA, 0.2 $\mathrm{mM}$ ethylene glycol-bis( $\beta$-aminoethyl ether)- $N, N, N^{\prime}, N^{\prime}$-tetraacetic acid (EGTA), $2 \mathrm{mM}$ dithiothreitol (DTT), $25 \%$ glycerol, $0.15 \mathrm{~mm}$ spermine, $0.75 \mathrm{mM}$ spermidine, $1 \mathrm{mM}$ phenylmethylsulfonyl fluoride, $0.4 \mathrm{M} \mathrm{NaCl}$ ]. The extract was recovered by centrifugation at $150,000 \times g$ for $90 \mathrm{~min}$ followed by dialysis against modified buffer $D$ (20 mM HEPES [pH 7.9], 20\% glycerol, $100 \mathrm{mM} \mathrm{KCl,} 0.2 \mathrm{mM}$ EDTA, $0.2 \mathrm{mM}$ EGTA, $2 \mathrm{mM}$ DTT, $1.0 \mathrm{mM}$ phenylmethylsulfonyl fluoride, $12.5 \mathrm{mM} \mathrm{MgCl}{ }_{2}$ ). The extract was stored in aliquots at $-70^{\circ} \mathrm{C}$.

DNase I footprinting. DNase I footprinting was carried out by a modification of the standard technique (8). Typically, 5 
to $10 \mathrm{ng}$ of end-labeled DNA was incubated with various amounts of nuclear extract protein in the presence of $15 \mu \mathrm{g}$ of poly $(\mathrm{dI}-\mathrm{dC})$ in a $120-\mu$ l reaction volume containing $6.1 \%$ glycerol, 0.07 mM EDTA, 0.07 mM EGTA, 7.2 mM HEPES (pH 7.9), $39 \mathrm{mM} \mathrm{KCl}$, and $7.5 \mathrm{mM} \mathrm{MgCl}_{2}$. The binding reactions were incubated at room temperature for $30 \mathrm{~min}$ and adjusted to a final $\mathrm{CaCl}_{2}$ concentration of $2 \mathrm{mM}$. Freshly diluted DNase I (Bethesda Research Laboratories, Inc.) was added to the reactions, and digestion was allowed to proceed for $4 \mathrm{~min}$ at room temperature. Digestion was stopped by adding 2 volumes of a mixture containing $100 \mathrm{mM}$ Tris

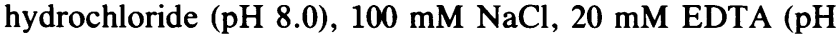
8.0), $0.1 \%$ sodium dodecyl sulfate, $100 \mu \mathrm{g}$ of proteinase $\mathrm{K}$ per $\mathrm{ml}$, and $100 \mu \mathrm{g}$ of tRNA per ml. Following incubation at $37^{\circ} \mathrm{C}$ for $20 \mathrm{~min}$, the samples were extracted with an equal volume of phenol-chloroform (phenol-chloroform-isoamyl alcohol, 25:24:1) and ethanol precipitated. The samples were suspended in $7 \mathrm{M}$ urea-dye mix and electrophoresed through 8\% polyacrylamide gels (acrylamide-bisacrylamide, 19:1) in $0.5 \times$ TBE buffer (0.045 M Tris, $0.045 \mathrm{M}$ boric acid, $1 \mathrm{mM}$ disodium EDTA). The gels were exposed to X-ray film overnight at $-70^{\circ} \mathrm{C}$ with an intensifying screen.

Gel mobility shift assays. Gel retardation assays were performed under previously reported conditions for E2F (26). Reaction mixtures consisted of 0.1 to $0.3 \mathrm{ng}$ of labeled promoter fragment and $6 \mu \mathrm{g}$ of HeLa nuclear extract protein in a buffer consisting of $20 \mathrm{mM}$ HEPES ( $\mathrm{pH} 7.9$ ), $40 \mathrm{mM}$ $\mathrm{KCl}, 1 \mathrm{mM} \mathrm{MgCl}{ }_{2}, 0.4 \mathrm{mM}$ DTT, $0.08 \mathrm{mM}$ EGTA, 4\% Ficoll (Pharmacia Fine Chemicals), and 0.04\% Nonidet P-40. Salmon sperm DNA $(2 \mu \mathrm{g})$ was added as nonspecific competitor DNA, and the final volume of the reaction mixtures was adjusted to $25 \mu \mathrm{l}$. Following incubation at room temperature for $30 \mathrm{~min}$, the reactions were loaded onto a $4 \%$ polyacrylamide gel (acrylamide-bisacrylamide, 30:0.8) in $0.25 \times \mathrm{TBE}$ and electrophoresed at $250 \mathrm{~V}$ for 1 to $2 \mathrm{~h}$. The gels were exposed to X-ray film overnight at $-70^{\circ} \mathrm{C}$ with an intensifying screen.

MPE footprinting. Methidiumpropyl-EDTA-Fe(II) (MPE) footprinting was carried out as described previously (15). Briefly, preparative gel shift reactions were incubated at room temperature for $30 \mathrm{~min}$, at which time a calculated volume of a mixture containing $500 \mu \mathrm{M}$ MPE, $500 \mu \mathrm{M}$ $\mathrm{Fe}\left(\mathrm{NH}_{4}\right)_{2}\left(\mathrm{SO}_{4}\right)_{2}$, and $20 \mathrm{mM}$ DTT was added to the binding reactions (final concentrations, $100 \mu \mathrm{M}$ MPE, $100 \mu \mathrm{M}$ $\mathrm{Fe}\left(\mathrm{NH}_{4}\right)_{2}\left(\mathrm{SO}_{4}\right)_{2}$, and $4 \mathrm{mM}$ DTT $)$. The reactions were then loaded and electrophoresed as normal, with $10 \mathrm{~min}$ allowed for the digestions to proceed prior to electrophoresis. Following brief autoradiography, the bands corresponding to the major E2F complex and free probe were isolated and the DNA was electrophoresed through $1 \%$ agarose gels onto NA45 paper (Schleicher \& Schuell Inc.). The DNA was then eluted, phenol-chloroform extracted, and ethanol precipitated. The resulting partial cleavage ladders were resolved on $8 \%$ sequencing gels and autoradiographed at $-70^{\circ} \mathrm{C}$.

Methylation interference assays. Partially methylated probe DNA was prepared by treating end-labeled probe DNA with dimethyl sulfate as described previously (16). This DNA was used in preparative gel shift reactions, which were loaded and electrophoresed as normal. The bands corresponding to the major E2F complex, minor E2F complex, and free probe were excised and processed as for MPE footprinting, except that the samples were cleaved with piperidine prior to electrophoresis.

Oligonucleotide-directed mutagenesis of the DHFR E2F site. A mutant with a mutation in the DHFR E2F consensus binding site was constructed by oligonucleotide-directed mutagenesis (14). To construct this mutant, a DHFR promoter fragment containing DHFR sequences from -239 to -22 was subcloned into M13mp18, and the resultant bacteriophage was passaged through Escherichia coli CJ236 (obtained from T. Kunkel, National Institute of Environmental Health Sciences), which is deficient in uracil- $N$-glycosylase and dUTPase activity (11). Uracil-containing single-stranded DNA was then purified and used as a template for secondstrand synthesis by using a mutagenic oligonucleotide of the sequence 5'-TGCAATTTCGTACCAAACTTG-3', which bears a 2-base mismatch (underlined) with the wildtype DHFR E2F consensus sequence. Briefly, $10 \mathrm{ng}$ of the mutagenic primer was annealed to $200 \mathrm{ng}$ of -239 template DNA, and second-strand synthesis was initiated by the addition of T4 DNA ligase (Boehringer Mannheim Biochemicals) and modified T7 DNA polymerase (Sequenase; U.S. Biochemical Corp.) to the reaction in a volume of $20 \mu \mathrm{l}$ (final buffer conditions, $20 \mathrm{mM}$ Tris [pH 7.5], $10 \mathrm{mM} \mathrm{MgCl} / 50$ $\mathrm{mM} \mathrm{NaCl}, 6.7 \mathrm{mM}$ DTT, $1 \mathrm{mM}$ ATP, $0.4 \mathrm{mM}$ dATP, $0.4 \mathrm{mM}$ dGTP, $0.4 \mathrm{mM} \mathrm{dCTP}$, and $0.4 \mathrm{mM}$ dTTP). Transformation of the synthesis products into $E$. coli $\mathrm{DH} 5 \alpha \mathrm{F}^{\prime}$ (Bethesda $\mathrm{Re}$ search Laboratories) allowed for the production of plaques, which were then screened for the mutation by DNA sequencing via the chain termination method (20).

In vitro transcription assays. In vitro transcription reactions were performed in a final volume of $25 \mu$ l containing $400 \mu \mathrm{M}$ ATP, $400 \mu \mathrm{M}$ CTP, $400 \mu \mathrm{M}$ UTP, $50 \mu \mathrm{M}\left[\alpha-{ }^{32} \mathrm{P}\right] \mathrm{GTP}$ (3,000 Ci/mmol; $10 \mu \mathrm{Ci}$ per reaction), $1 \mathrm{mM}$ creatine phosphate, and $140 \mu \mathrm{M}$ EDTA. The transcription reactions were initiated by the addition of linearized plasmid template DNA and $15 \mu \mathrm{l}$ of nuclear extract (150 $\mu \mathrm{g}$ of protein). The reactions were incubated at $30^{\circ} \mathrm{C}$ for $60 \mathrm{~min}$ and stopped by the addition of a mixture containing $8 \mathrm{M}$ urea, sodium dodecyl sulfate, $0.5 \% 10 \mathrm{mM}$ EDTA, and $10 \mathrm{mM}$ Tris $(\mathrm{pH}$ 8.0). A 494-nucleotide Sp6 transcript was included in the stop mixture as a control for sample recovery during processing. The samples were phenol-chloroform extracted twice, ethanol precipitated, and electrophoresed on $4 \%$ polyacrylamide-7 $\mathrm{M}$ urea denaturing gels in $0.5 \times \mathrm{TBE}$. Autoradiography was performed as described above.

Transient-expression assays of DHFR expression. HeLa cells were maintained in monolayer in Eagle minimal essential medium supplemented with $10 \%$ defined calf serum (Hyclone). The -239 and -239 mutant constructs were transfected into HeLa cells by the calcium phosphate coprecipitation method (9). Plasmid DNA $(10 \mu \mathrm{g})$ was precipitated for $30 \mathrm{~min}$ in HEPES-buffered saline by the addition of $\mathrm{CaCl}_{2}$ to $6.0 \mathrm{mM}$. The DNA precipitate in $500 \mu \mathrm{l}$ was layered onto a washed, well-drained monolayer containing ca. $10^{6}$ cells per $10-\mathrm{cm}$ dish. Complete medium was added after $30 \mathrm{~min}$. After 4 hours, the medium was aspirated and the cells were treated with $12.5 \%$ glycerol in HEPES-buffered saline for 4 min; the monolayer was then washed and complete medium was added. The cells were incubated for $48 \mathrm{~h}$ before being harvested. Freeze-thaw lysates were assayed for protein content by the Bradford method (2), and samples normalized for protein content were assayed for chloramphenicol acetyltransferase activity by using $\left[{ }^{14} \mathrm{C}\right]$ chloramphenicol as a substrate. Acetylated $\left[{ }^{14} \mathrm{C}\right]$ chloramphenicol was separated from the nonacetylated forms by thin-layer chromatography, and the thin-layer chromatography plate was autoradiographed. The percentage conversion of chloramphenicol to acetylated chloramphenicol was determined by liquid scintillation counting of isolated spots from thin-layer chromatography plates. 


\section{RESULTS}

Multiple DNA-protein interactions within the DHFR 5'flanking region. Initial studies of the transcriptional activity of a series of DHFR promoter deletion constructs indicated that a construct containing from -239 to -23 relative to ATG maximally expresses DHFR in vitro and in vivo, while a construct containing from -103 to -18 has no transcriptional activity (A. Swick, M. Blake, J. Kahn, and J. C. Azizkhan, submitted for publication). The differences in promoter activity displayed by progressive deletions of the DHFR promoter suggested that the amount of 5 '-flanking sequence affects the efficiency of DHFR transcription. All of the numbering of the DHFR 5'-flanking region is relative to ATG, since the hamster DHFR gene contains a major and minor transcription start site at positions -63 and -107 , respectively (18).

In an attempt to correlate protein-DNA interactions within the DHFR 5'-flanking region with promoter activity, a fragment from the BssHII site at -239 to the StyI site at -23 was mapped by DNase I footprinting. Figure 1 shows the results of a protein titration of HeLa nuclear extract on this fragment. Three regions of protein-DNA interaction are seen on the lower (noncoding) strand of the -239 promoter fragment. Region 1 overlies the major transcription start site and is evidenced by shifts in DNase I-hypersensitive sites from -46 and -70 in the free DNA reaction to -49 and -66 in the DNA-protein reaction. Region 2 is a footprint extending from -95 to -115 and includes a GC box overlying the DHFR secondary transcription start site at -107 . Region 3 is a footprint extending from -136 to -201 and includes three GC boxes (part of this region is not included in Fig. 1 so that the interaction in region 1 can be seen). The observed shift in DNase I-hypersensitive sites in the region overlying the major transcription start site lies within a conserved sequence previously reported as "element 2" (1) and requires $240 \mu \mathrm{g}$ of nuclear extract protein under these conditions, which is 4 times the amount of protein required to footprint the GC boxes. We wish to note a correction in the published hamster DHFR sequence; the nucleotide at position -68 is $\mathrm{C}$ rather than the A previously reported (1).

DNase I analysis of the region from -50 to -65 is seen more clearly in Fig. 2, in which a shorter probe lacking the GC box motifs (from the HaeIII site at -103 to the Sau3AI site at -19) is used. The sequence between the hypersensitive sites at -49 and $-66,5^{\prime}$-CAATTTCGCGCCAAAC-3', corresponds to two potential overlapping binding sites for the cellular transcription factor E2F (Fig. 2, bottom). An E2F binding site, 5'-TTTCGCGC-3', appears in the DHFR promoter from -62 to -55 . A seven-of-eight-nucleotide match to this sequence, $5^{\prime}$-TTTGGCGC-3', is found from positions -58 to -51 on the lower strand (Fig. 2, bottom); this sequence is also capable of binding E2F (S. W. Hiebert, J. Nevins, M. Blake, and J. C. Azizkhan, unpublished data). The DNase I cleavage in this region is remarkably hindered even in the absence of protein (Fig. 2, middle two lanes), suggesting that this sequence forms a secondary structure that is resistant to DNase I digestion. For the purposes of analysis, we have designated the two recognition sequences as site 1 and site 2 , although it is not entirely clear that both of these sites are functional. Since they are overlapping, we will refer to the two overlapping recognition sites for the transcription factor E2F in the DHFR promoter collectively as the E2F site. A comparison of the DHFR E2F site with other reported E2F sites is shown in Table 1. The E2, E1A, and c-myc P2 promoters each contain two separate E2F

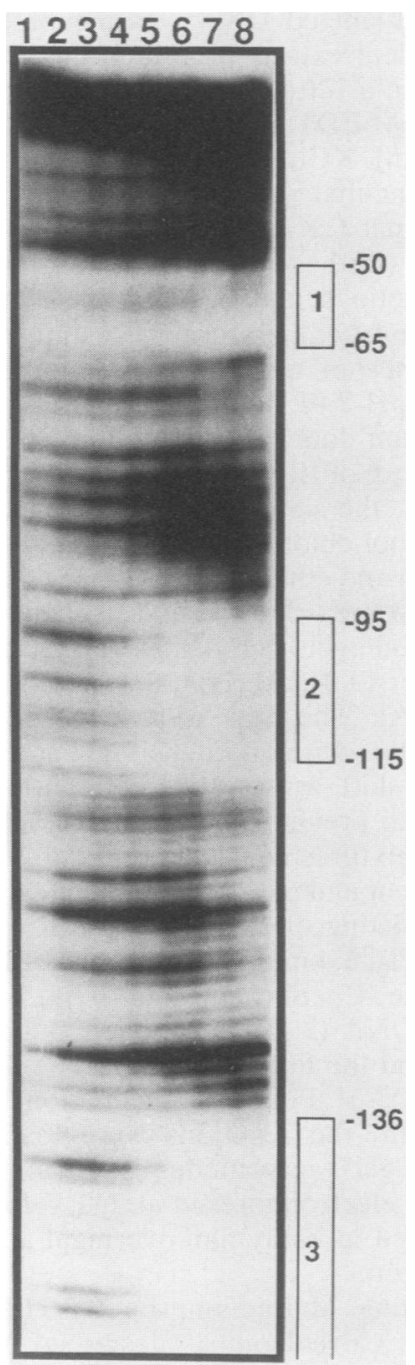

FIG. 1. Multiple protein-DNA associations on the DHFR promoter in vitro. An EcoRI-PstI fragment containing from -239 to -23 of the DHFR promoter was asymmetrically end labeled on the lower strand by a Klenow fill-in reaction, and $5 \mathrm{ng}$ of the resulting probe was incubated with $15 \mu \mathrm{g}$ of poly(dI-dC) and various amounts of HeLa nuclear extract as described in Materials and Methods. Nucleotide positions of the interactions are noted on the side of the diagram by boxes. Lanes 1 to 8 contain $0,7.5,15,30,60,120,240$, and $480 \mu \mathrm{g}$ of nuclear extract protein, respectively. DNase I concentrations used in lanes 1 to 8 were $0.01,0.06,0.13,0.25,0.5$, 1,2 , and $4 \mu \mathrm{g} / \mathrm{ml}$, respectively. An expanded view of the sequence contained in boxed region 1 is shown in Fig. 2.

binding sites. The DHFR site differs from the other sites in its location $3^{\prime}$ to the major DHFR transcription start site and in the fact that either there is only one site or the two sites are not tandemly arranged. One of the reported E2F sites (E1A site 1) possesses a similar dyad symmetry to the DHFR E2F site (Table 1).

A specific gel shift pattern is given by E2F in HeLa nuclear extracts with the DHFR promoter. To confirm that the interaction seen in this region was due to E2F, we used gel shift assays. The -103 promoter fragment was chosen for a study of the interaction of E2F with the DHFR promoter, since it contains no GC boxes and could be more clearly resolved. As a positive control for the interaction of E2F 


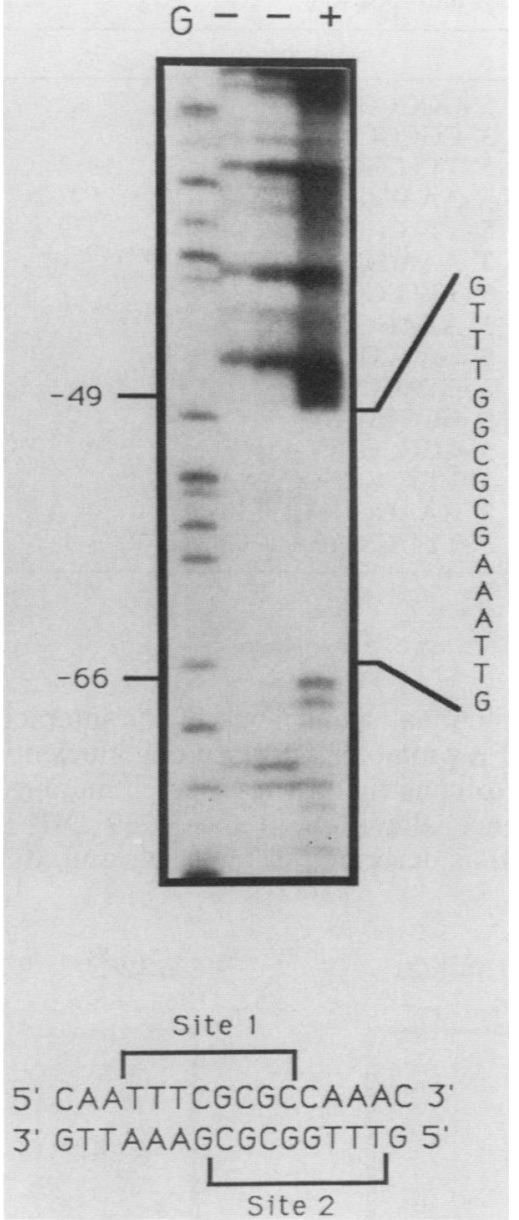

FIG. 2. Two shifts in DNase I-hypersensitive sites border a potential E2F binding site in the DHFR promoter. An EcoRI-PstI fragment containing from -103 to -17 of the DHFR promoter was asymmetrically labeled on the lower strand by a Klenow fill-in reaction, and $2 \mathrm{ng}$ of the resulting probe was incubated with $15 \mu \mathrm{g}$ of poly (dI-dC) and either no protein (lanes -) or $240 \mu \mathrm{g}$ of HeLa nuclear extract protein (lane + ) as described in Materials and Methods. The sequence bordered by the DNase I-hypersensitive sites at -49 and -66 is presented on the right side of the figure. Lane $G$ is a $G$ ladder marker (16), lanes - are free DNA (DNase I concentration of $0.01 \mu \mathrm{g} / \mathrm{ml}$ ), and lane + represents the DNA-plusprotein reaction (DNase I concentration, $\mu \mathrm{g} / \mathrm{ml}$ ). The diagram below the figure shows the sequence of the potential DHFR E2F site, with the E2F consensus binding sequences indicated by brackets.

with the -103 promoter fragment, a gel shift reaction was performed by using partially purified E2F isolated from adenovirus-infected HeLa cells (the kind gift of J. Nevins, Duke University) under conditions of low $\mathbf{M g}^{2+}$ as described previously (26). Incubation of $1 \mu$ l of partially purified E2F with this fragment resulted in the formation of both a major and a minor complex (Fig. 3, lane b). Incubation of the -103 promoter fragment with crude nuclear HeLa extract resulted in the formation of multiple complexes, including complexes comigrating with those formed with partially purified E2F (Fig. 3, lanes c and d). Two additional complexes were detected in our gel shift assays with crude nuclear extracts; the lowest complex was not reproducibly seen in our assays and may be nonspecific. The complex migrating above the E2F complexes was not inhibited by a DHFR E2F site oligonucleotide (see Fig. 6) and is also thought to be nonspecific.

Fine-scale mapping of the interaction of E2F with the DHFR promoter by MPE-Fe(II) footprinting and methylation interference analysis. To further delineate the interaction of E2F with the DHFR promoter, we used MPE footprinting (15). MPE and other methods of chemical footprinting offer the advantage of a smaller cleavage probe with less sequence specificity than DNase I for protection experiments. Moreover, MPE does not have a functional requirement for $\mathbf{M g}^{\mathbf{2}}$, which inhibits the formation of E2F complexes in our gel retardation assays. Indeed, the inclusion of $7.5 \mathrm{mM} \mathrm{MgCl}$ in the DNase I footprinting reactions probably inhibited the binding of E2F to the DHFR promoter, thus explaining the large amount of nuclear extract protein required to generate the observed shifts in DNase I hypersensitivity. MPE (kindly supplied by P. Dervan, California Institute of Technology) was used to partially cleave binding reactions, which were then electrophoresed on native $4 \%$ polyacrylamide gels. Bands corresponding to the free DNA and bound complexes were then excised, and the resulting cleavage products were resolved on sequencing gels. The MPE footprinting analysis of the DHFR promoter (from -103) is presented in Fig. 4. The region of the DHFR promoter protected from MPE cleavage in the major E2F complex extends from -63 to -49 on the upper strand and from -51 to -64 on the lower strand. The footprint includes the entire DHFR E2F site.

Methylation interference analysis of the shifted bands corresponding to the major and minor E2F complexes resulted in an interference pattern centered about the E2F consensus on both strands, indicating $G$ residues that, when methylated, interfere with E2F binding to the DHFR promoter. Figure 5 shows the methylation interference patterns obtained on the upper and lower strands. The upper strand contains two $G$ residues within the E2F site that interfere with E2F binding when methylated. On the lower strand, four $G$ residues within the footprinted region interfere with binding when methylated. The methylation interference pattern on the lower strand includes an additional $G$ residue at -54 that is not contained within the E2F consensus binding site on the upper strand, suggesting that E2F is in close proximity to this $G$ residue when bound. Methylation of a $G$ residue at -59 interferes with $\mathrm{E} 2 \mathrm{~F}$ binding, although not as completely as methylation of the other $G$ residues in the binding site does. The same methylation interference pattern is displayed by the major and minor E2F complexes. The lower portion of Fig. 5 shows a schematic diagram of the regions protected by MPE footprinting, along with the methylation interference patterns of both strands.

Analysis of a mutation which abolishes the interaction of E2F with the DHFR promoter in vitro. Further evidence of the interaction of E2F with the DHFR promoter was provided by the analysis of a specific mutation which abolishes the DHFR E2F binding site. Oligonucleotides were synthesized that contained both the wild-type DHFR E2F binding site and a mutant DHFR E2F binding site. This mutation changes the sequence at nucleotide positions -62 to -51 from 5'-TTTCGCGCCAAA-3' to 5'-TTTCGTACCAAA-3' (substitution underlined), simultaneously abolishing both potential overlapping E2F sites. Annealed wild-type and mutant oligonucleotides were then examined for their ability to compete for the E2F complexes generated in the gel shift assay by using HeLa nuclear extract (Fig. 6). Although the wild-type oligonucleotide completed for the major and minor E2F complexes at a 25 -fold molar excess, the mutant oligonucleotide failed to compete for complex formation, even 
TABLE 1. Summary of E2F recognition sequences and location

\begin{tabular}{|c|c|c|c|c|}
\hline Gene & Promoter & Location of interaction ${ }^{a}$ & Sequence & Reference \\
\hline E2 & $\begin{array}{l}\text { I } \\
\text { II }\end{array}$ & $\begin{array}{l}-43 \text { to }-36 \\
-67 \text { to }-60\end{array}$ & $\begin{array}{l}\text { 5'-GCGCGAAA-3' } \\
\text { 3'-CGCGCTTT-5' } \\
\text { 5'-TTTCGCGC-3' } \\
\text { 3'-AAAGCGCG-5' }\end{array}$ & 12 \\
\hline E1A enhancer & $\begin{array}{l}\text { I } \\
\text { II }\end{array}$ & $\begin{array}{l}-224 \text { to }-217 \\
-287 \text { to }-280\end{array}$ & $\begin{array}{l}\text { 5'-TTTCGCGGGAAA-3' } \\
\text { 3'-AAAGCGCCCTTT-5' } \\
\text { 5'-TTTCGCGC-3' } \\
\text { 3'-AAAGCGCG-5' }\end{array}$ & 13 \\
\hline$c-m y c(\mathrm{P} 2)$ & I & $\begin{array}{l}-42 \text { to }-35 \\
-65 \text { to }-58\end{array}$ & $\begin{array}{l}\text { 5'-GATCGCGC-3'b } \\
\text { 3'-CTAGCGCG-5' }^{\prime} \text { 5'-GCGGGAAA-3' } \\
\text { 3'-CGCCCTTT-5' }\end{array}$ & 10,24 \\
\hline $\begin{array}{l}\text { DHFR } \\
\text { Consensus binding site }\end{array}$ & & +2 to +13 & $\begin{array}{l}\text { 5'-TTTCGCGCCAAA-3' } \\
\text { 3'-AAAGCGCGGTTT-5' } \\
\text { 5'-TTT(C/G)(G/C)CG(C/G)-3' }\end{array}$ & \\
\hline
\end{tabular}

${ }^{a}$ All numbering is relative to the major start of transcription.

${ }^{b}$ Weak binding site.

under conditions of 200 -fold molar excess. An additional complex migrating above the E2F complexes was not competed for by either oligonucleotide and is thought to be nonspecific.

E2F is required for efficient DHFR transcription in vitro. To

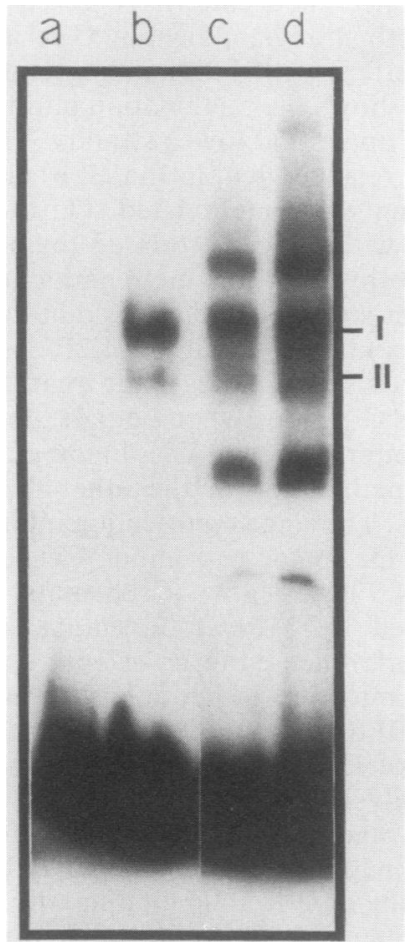

FIG. 3. Complexes comigrating with partially purified E2F are formed on the DHFR promoter in HeLa crude nuclear extracts. The -103 to -17 DHFR promoter fragment was end labeled and incubated alone (lane a), with $1 \mu$ l of partially pure E2F (lane b), or $6 \mu \mathrm{g}$ of HeLa crude nuclear extract (lanes $\mathrm{c}$ and d). Lanes b and d contain $1 \mu \mathrm{g}$ of salmon sperm DNA as a nonspecific competitor; lane c contains $2 \mu \mathrm{g}$ of salmon sperm DNA. The major (I) and minor (II) complexes of E2F with the DHFR promoter are noted on the side of the figure. Additional complexes seen in lanes $c$ and $d$ are not due to the E2F interaction and are addressed in the text. assess the functional significance of the interaction of E2F with the DHFR promoter, we used oligonucleotide-directed mutagenesis to construct a site-directed mutant bearing the above sequence alteration in the -239 DHFR promoter construct (14) as described in Materials and Methods. This



FIG. 4. MPE footprinting analysis of the major E2F complex with the DHFR promoter. The -103 to -17 DHFR promoter fragment was digested with KpnI-HindIII or EcoRI-PstI to selectively label the upper and the lower strand, respectively. These probes were then used in binding reactions with HeLa nuclear extract. These reactions were partially digested with MPE and separated on $4 \%$ native polyacrylamide gels. Shifted bands corresponding to the major E2F complex on the upper strand or the lower strand were excised from the gels. DNA from the complexes and the free probe bands was then eluted and resolved on $8 \%$ sequencing gels. Protected regions of the promoter are indicated by the DNA sequence. 


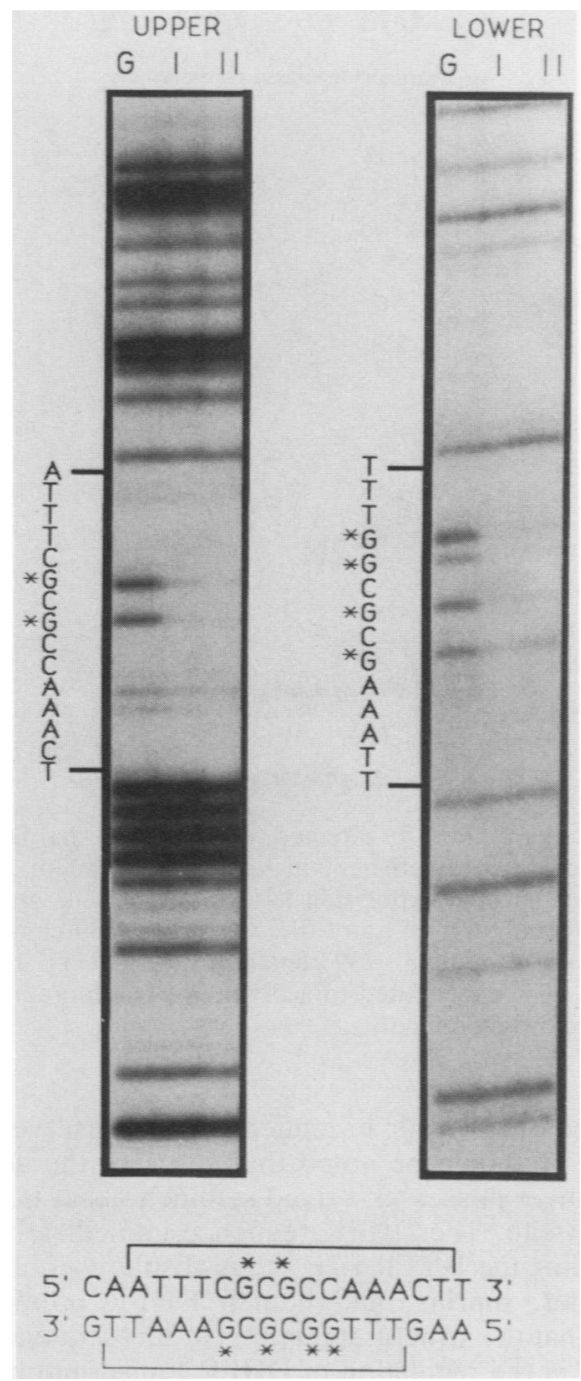

FIG. 5. Methylation interference analysis of the major and minor E2F complexes with the DHFR promoter. The -103 to -17 DHFR promoter fragment was digested with KpnI-HindIII or EcoRI-PstI to selectively label the upper and the lower strand, respectively. The probe DNA was then partially methylated with dimethyl sulfate as described previously (16). These probes were used in binding reactions with $\mathrm{HeLa}$ nuclear extract and electrophoresed on $4 \%$ native polyacrylamide gels. Shifted bands corresponding to the major and minor E2F complexes on the upper strand or the lower strand were excised from the gels, as well as bands corresponding to the free probe DNA. DNA eluted from the bands was cleaved with piperidine and resolved on $8 \%$ sequencing gels. $G$ residues that interfere with complex formation when methylated are indicated by asterisks.

mutant does not bind partially purified E2F in the gel shift assay when introduced into the -239 promoter construct (data not shown).

The activity of the E2F mutant DHFR promoter, which does not bind E2F, was compared with that of the wild-type -239 construct in assays of transcriptional activity in vitro by using HeLa nuclear extracts (Fig. 7). The two RNA transcripts shown represent both the major DHFR transcription start site $(-63)$ and the minor start site $(-107)$, which have been reported previously (18). A 494-base transcript was included as a control for sample recovery. In three separate experiments with duplicate samples, transcription

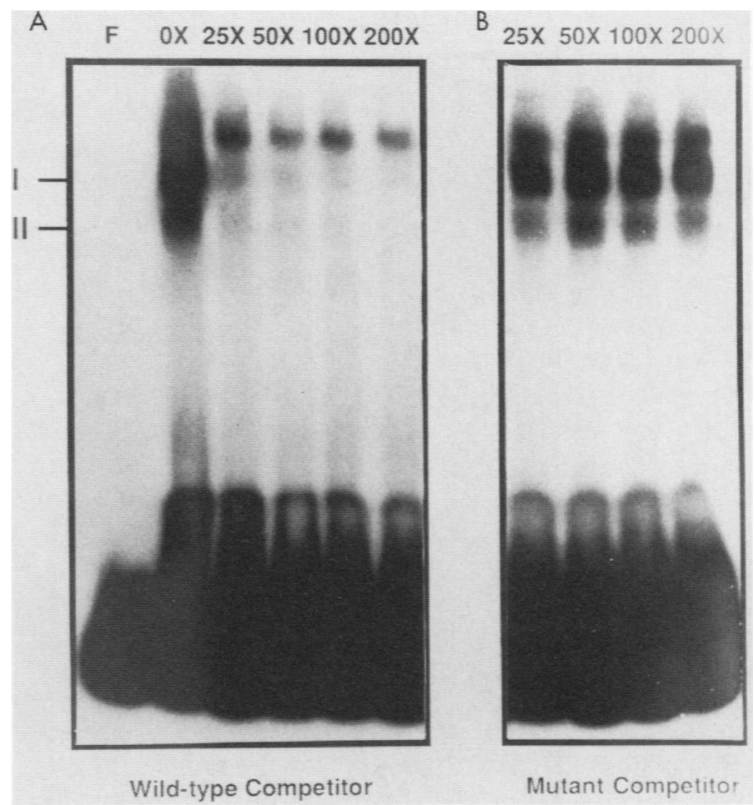

FIG. 6. The E2F complexes on the DHFR promoter are specifically competed for by the wild-type DHFR E2F binding site but not by a mutant DHFR E2F binding site. Binding reactions of HeLa nuclear extract were preincubated with annealed oligonucleotides bearing either a wild-type DHFR E2F binding sequence, (5'TTTCGCGCCAAA-3') or a mutant DHFR E2F binding sequence (5'-TTTCGTACCAAA-3') for $10 \mathrm{~min}$ prior to the addition of endlabeled -103 promoter fragment. The molar excess of competitor DNA is indicated above each lane. (A) Lanes: $F$, free probe; $0 \times$, no competitor; $25 \times$ through $200 \times$, competition with wild-type oligonucleotide. (B) Competition with mutant oligonucleotide.

from the mutant template was reduced two- to fivefold when compared with that of the wild-type template. It should be noted that the relative transcription from the major and the minor start sites (4:1) appears to remain the same and that the major start site of transcription is not preceptibly altered, even though the E2F interaction occurs immediately $3^{\prime}$ to the major DHFR transcription start site at -63 .

E2F is required for efficient DHFR expression in vivo. Transient-expression assays were used to examine the effects of abolishing E2F binding in vivo (Fig. 8). Constructs bearing the wild-type -239 construct or mutant -239 DHFR construct fused to the bacterial chloramphenicol acetyltransferase gene were introduced into $\mathrm{HeLa}$ cells via the calcium phosphate coprecipitation method of transfection. Comparison of the relative chloramphenicol acetyltransferase activity of the wild-type versus the mutant construct in multiple experiments indicates a greater than fivefold reduction $(5.26$ \pm 1.14 [standard error of the mean]; $n=7$ ) in chloramphenicol acetyltransferase activity as measured by the percent conversion of the nonacetylated to the acetylated form. These results are consistent with the in vitro transcription data and demonstrate the importance of the E2F interaction in DHFR expression.

\section{DISCUSSION}

The data presented in this paper demonstrate that multiple protein-DNA interactions occur in the immediate 5 '-flanking region of the hamster DHFR gene. One of these interactions involves the cellular transcription factor E2F, which binds to a conserved region of promoter sequence $3^{\prime}$ to the major 




FIG. 7. A specific site-directed mutation of the DHFR E2F binding site abolishes efficient in vitro transcription of the DHFR promoter in HeLa nuclear extracts. Wild-type and E2F mutant -239 constructs $(0.5 \mu \mathrm{g})$ were digested with $S c a$ I to generate linear templates for in vitro runoff transcription. These templates were incubated with $\mathrm{HeLa}$ nuclear extract in the presence of ribonucleotides (including [ $\left.\alpha^{32} \mathrm{P}\right] \mathrm{GTP}$ ), processed, and electrophoresed on $4 \%$ sequencing gels as described in Materials and Methods. A 494-base Sp6 transcript was included as a control for sample recovery. Lanes: M, $\phi X 174$ HaeIII; WT, $0.5 \mu \mathrm{g}$ of wild-type template; MUT, $0.5 \mu \mathrm{g}$ of mutant template. The positions of the marker bands, 494-base transcript, and DHFR major and minor transcripts are indicated.

transcription start site. The DHFR site possesses dyad symmetry and includes two potential overlapping E2F binding sites lying in opposite orientation. A mutation which abolishes the interaction of E2F with the DHFR promoter reduces transcription in vitro by two- to fivefold and transient DHFR-CAT expression in vivo by fivefold. This is the first demonstration of E2F binding to the DHFR gene and of the requirement for E2F for efficient DHFR expression.

Several findings suggest that the factor interacting with this region of the DHFR promoter is E2F. First, the region of the DHFR promoter protected by this factor in enzymatic and chemical footprinting experiments contains two recognition sequences for E2F. Second, specific gel shift complexes comigrating with those generated by partially pure E2F on the DHFR promoter are found in crude nuclear extracts from HeLa cells. Third, the methylation interference analysis of these complexes demonstrates multiple protein-DNA contacts within the DHFR E2F site. Finally, the complexes comigrating with partially purified E2F in HeLa crude nuclear extract can be competed for by an oligonucleotide containing the DHFR E2F binding site, but not by an oligonucleotide bearing a mutation of this site which abolishes the E2F consensus binding site.

The DHFR E2F binding site is unique among reported E2F binding sites in its location $3^{\prime}$ to the transcription start sites and in its nontandem arrangement. Previously reported E2F sites within the adenovirus E2 and E1A and the human

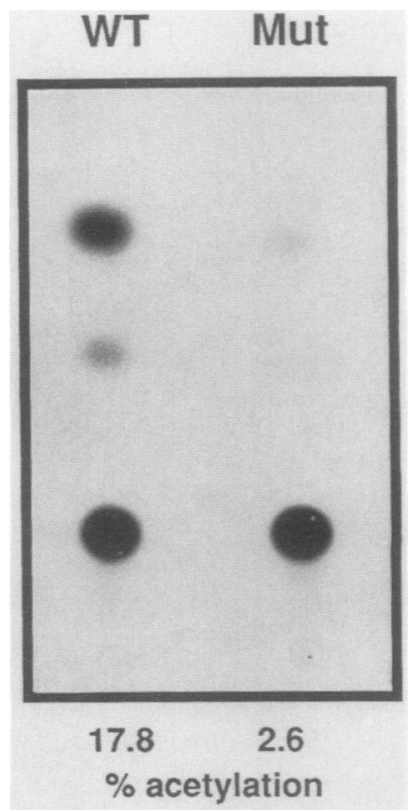

FIG. 8. A specific site-directed mutation of the DHFR E2F binding site abolishes efficient in vivo expression of the DHFR promoter in transient-expression assays. HeLa cells in monolayer were transfected with $10 \mu \mathrm{g}$ of the wild-type -239 construct (lane WT) or $10 \mu \mathrm{g}$ of mutant -239 construct (lane MUT). The percent conversion of nonacetylated to acetylated $\left[{ }^{14} \mathrm{C}\right]$ chloramphenicol is indicated below each lane.

c-myc promoters occur in tandem, with conserved spacing (Table 1). It should be noted that site 1 of the adenovirus E1A enhancer possesses a dyad symmetry that is similar to the DHFR site. The DHFR sequence immediately flanking and including the DHFR E2F site is absolutely conserved in the hamster, murine, and human DHFR promoters (1), implying that the structural features of this sequence may be important in the regulation of DHFR transcription. It is not entirely unprecedented that a sequence element $3^{\prime}$ to the mRNA cap site is involved in transcriptional regulation (25). The location of the DHFR E2F site 3 ' to the major transcription start site is interesting in that this sequence, which exhibits secondary structure in vitro, is represented in both the major and minor DHFR RNA transcripts. We are investigating the possibility of an additional role of the E2F binding site (or factor interacting with this sequence) in regulating DHFR mRNA stability. In contrast to those of the human (3) and hamster (18) DHFR promoters, the major transcription start site in the murine DHFR gene has been mapped immediately $3^{\prime}$ to the DHFR E2F site (7); the significance of this difference is presently unknown.

The E2F factor may also be involved in the regulation of DHFR transcription in response to various factors. The increased expression of DHFR in adenovirus-infected cells may involve the E2F interaction with the DHFR promoter. Previous work has suggested that both a transcriptional activation of DHFR expression (7) and a transient stabilization of DHFR transcripts within the nucleus (27) result from adenovirus infection.

We are also investigating the possible role of $\mathrm{E} 2 \mathrm{~F}$ in the regulation of DHFR expression within the cell cycle and in response to growth stimuli. Cellular E1A-like factors have been implicated in the activation of E2F (19) and may be involved in the regulation of DHFR gene expression via the 
E2F factor. The following cellular genes that are under growth control contain E2F sites: c-myc, N-myc, c-myb, and the EGF receptor gene (M. Mudryj, S. Hiebert, and J. Nevins, submitted for publication). The c-myc proto-oncogene appears to require E2F for basal-level expression and trans-activation by E1A $(10,24)$. In the $5^{\prime}$ sequence of an additional growth-regulated gene, the transferrin receptor gene (17), we have noticed a intragenic E2F binding site.

It is not yet clear whether the observed gel shift complexes seen with E2F on the DHFR promoter are due to occupancy of one site or both sites. We are presently constructing site-directed mutants which abolish each of the E2F binding sites separately to further examine the interaction of E2F with the DHFR promoter. Earlier studies of the E2F factor demonstrated very low binding activity in non-adenovirusinfected HeLa cells $(12,22)$. However, we routinely detect E2F in our binding assays when using extracts from uninfected HeLa cells. The reason for this apparent difference is unknown, although we have modified the extract preparation procedure.

Functional analysis of the DHFR E2F mutant revealed a significant reduction in DHFR expression in vitro and in vivo. Although this mutation reduced transcription two- to fivefold, the relative ratio of transcripts from the two DHFR transcription start sites $(4: 1)$ and the position of the major start site remained the same. Therefore, we do not believe that E2F is required to specify the start site of DHFR transcription, nor that it affects the relative use of either the major or minor transcription start sites. It has been suggested that $\mathrm{GC}$ boxes may have a role in specifying the start site for promoters lacking the TATAA sequence element, and it is possible that interactions at the GC boxes of the DHFR promoter are responsible for the placement of the major and minor transcription start sites.

Binding of a factor to the GC boxes within the DHFR promoter has been shown to be required for DHFR transcription (Swick et al., submitted). We have shown here that the interaction of E2F with the DHFR promoter is required for efficient DHFR expression. Additional regions of conserved DNA sequence within the promoter region may also have functional importance, and they are currently being examined by site-directed mutagenesis. Further analysis of the interactions of E2F, Sp1, and additional factors with the DHFR promoter region will clarify the requirements for DHFR transcription and regulation.

\section{ACKNOWLEDGMENTS}

This work has been supported by research grant C.D.317 from the American Cancer Society and a Basil O'Connor Starter Scholar Award from the March of Dimes. J.C.A. is the recipient of a Junior Faculty Research Award from the American Cancer Society.

We thank Joseph Nevins and Scott Hiebert for providing partially pure E2F, participating in helpful discussions, and communicating data prior to publication. We are also indebted to Ben Van Houten and Ryszard Kole for technical advice, to David Lee for synthesis of oligonucleotides, and to Jeanne Kahn for technical assistance. We also thank Andrew Swick for technical assistance with the transfections and Robert Jambou and Al Baldwin for helpful discussions and critical review of the manuscript.

\section{LITERATURE CITED}

1. Azizkhan, J. C., J. Vaughn, R. J. Christy, and J. L. Hamlin. 1986. Nucleotide sequence and nuclease hypersensitivity of the Chinese hamster dihydrofolate reductase gene promoter. Biochemistry 25:6228-6236.

2. Bradford, M. M. 1976. A rapid and sensitive method for the quantitation of microgram quantities of protein utilizing the principle of protein dye binding. Anal. Biochem. 72:248-254.

3. Chen, M. T., A. D. Shimada, A. Moulton, R. K. Cline, J. Humphries, J. Maizel, and A. W. Neinhuis. 1984. The functional human dihydrofolate reductase gene. J. Biol. Chem. 259:39333943.

4. Dignam, J. D., R. L. Lebovitz, and R. G. Roeder. 1983. Accurate transcription initiation by RNA polymerase II in a soluble extract from isolated mammalian nuclei. Nucleic Acids Res. 11:1475-1489.

5. Dynan, W. S., S. Sazer, R. Tjian, and R. Schimke. 1986. Transcription factor $\mathrm{Sp} 1$ recognizes a DNA sequence in the mouse dihydrofolate reductase promoter. Nature (London) 319: 246-248.

6. Farnham, P. J., and R. T. Schimke. 1985. Transcriptional regulation of mouse dihydrofolate reductase in the cell cycle. $\mathbf{J}$. Biol. Chem. 260:7675-7680.

7. Farnham, P. J., and R. T. Schimke. 1986. In vitro transcription and delimitation of promoter elements of the murine dihydrofolate reductase gene. Mol. Cell. Biol. 6:2392-2401.

8. Galas, D. J., and A. Schmitz. 1978. DNAse footprinting: a simple method for the detection of protein-DNA binding specificity. Nucleic Acids Res. 5:3158-3170.

9. Graham, F. L., and A. J. van der Eb. 1973. Transformation of rat cells by DNA of human adenovirus 5 . Virology 52:456-467.

10. Hiebert, S. W., M. Lipp, and J. Nevins. 1989. E1A-dependent trans-activation of the human $M Y C$ promoter is mediated by the E2F factor. Proc. Natl. Acad. Sci. USA 86:3594-3598.

11. Joyce, C. M., and N. D. F. Grindley. 1984. Method for determining whether a gene of Escherichia coli is essential: application to the polA gene. J. Bacteriol. 158:636-643.

12. Kovesdi, I., R. Reichel, and J. R. Nevins. 1986. Identification of a cellular transcription factor involved in E1A trans-activation. Cell 45:219-228.

13. Kovesdi, I., R. Reichel, and J. R. Nevins. 1987. Role of an adenovirus E2 promoter binding factor in E1A-mediated coordinate gene control. Proc. Natl. Acad. Sci. USA 84:2180-2184.

14. Kunkel, T. A., J. D. Roberts, and R. A. Zakour. 1987. Rapid and efficient site-directed mutagenesis without phenotypic selection. Methods Enzymol. 154:367-382.

15. Landolfi, N. F., X-M. Yin, J. D. Capra, and P. W. Tucker. 1989. Protection analysis (or "footprinting") of specific protein-DNA complexes in crude nuclear extracts using methidiumpropylEDTA-iron(II). Biotechniques 7:500-504.

16. Maxam, A. M., and W. Gilbert. 1980. Sequencing end-labeled DNA with base-specific chemical cleavages. Methods Enzymol. 65:499-560.

17. Miskimins, W. K., A. McClelland, M. P. Roberts, and F. H. Ruddle. 1986. Cell proliferation and expression of the transferrin receptor gene: promoter sequence homologies and protein interactions. J. Cell. Biol. 103:1781-1788.

18. Mitchell, P. J., A. M. Carothers, J. H. Han, J. D. Harding, E. Kas, L. Venolia, and L. A. Chasin. 1986. Multiple transcription start sites, DNase I-hypersensitive sites, and an opposite-strand exon in the 5' region of the $\mathrm{CHO} \mathrm{dfhr}$ gene. Mol. Cell. Biol. 6:425-440.

19. Reichel, R., I. Kovesdi, and J. R. Nevins. 1987. Developmental control of a factor that is also regulated by the E1A gene product. Cell 48:501-506.

20. Sanger, F., S. Nicklen, and A. R. Coulson. 1977. DNA sequencing with chain-terminating inhibitors. Proc. Natl. Acad. Sci. USA 74:5463-5467.

21. Santiago, C., M. Collins, and L. F. Johnson. 1984. In vitro and in vivo analysis of dihydrofolate reductase gene transcription in serum-stimulated mouse fibroblasts. J. Cell. Physiol. 118:79-86.

22. SivaRaman, L., and B. Thimmappaya. 1987. Two promoterspecific host factors interact with adjacent sequences in an E1A-inducible adenovirus promoter. Proc. Natl. Acad. Sci. USA 84:6112-6116.

23. Stryer, L. 1975 . Biochemistry, p. 510-538. W. H. Freeman and Co., New York.

24. Thalmeier, K., H. Synovzik, R. Mertz, E. Winnacker, and $M$. Lipp. 1989. Nuclear factor E2F mediates basic transcription and trans-activation by Ela of the human myc promoter. Genes 
Dev. 3:527-536.

25. Toohey, M. G., and K. A. Jones. 1989. In vitro formation of short RNA polymerase II transcripts that terminate within the HIV-1 and HIV-2 promoter-proximal downstream region. Genes Dev. 3:265-282.

26. Yee, A. S., P. Raychaudhuri, L. Jakoi, and J. R. Nevins. 1989.
The adenovirus-inducible transcription factor E2F stimulates transcription after specific DNA binding. Mol. Cell. Biol. 9: 578-589.

27. Yoder, S. S., and S. M. Berget. 1985. Post-transcriptional control of DHFR gene expression during adenovirus 2 infection. J. Virol. 54:72-77. 